\title{
PAPER
}

1

I

Cite this: DOI: 10.1039/c5ta02130h
10

\section{Wettability of hierarchically-textured ceramic coatings produced by suspension HVOF spraying $\dagger$}

\author{
Feifei Zhang, ${ }^{a}$ Ben W. Robinson, ${ }^{b}$ Heidi de Villiers-Lovelock, ${ }^{c}$ Robert J. K. Wood ${ }^{a}$
} and Shun Cai Wang*a

A novel but simple path for the preparation of superhydrophobic and superhydrophilic coatings has been demonstrated via a recently developed technology, namely suspension high velocity oxy-fuel spraying. Potential uses for robust superhydrophobic coatings include antifouling applications such as aeroplane wings, ship hulls, offshore wind turbine blades, or the above-deck structures on ice breaker vessels. Several fabrication techniques have been reported for preparing inorganic superhydrophobic surfaces, but existing coatings either lack the necessary robustness for engineering applications and/or their deposition methods are not suitable for industrial scale-up. In this work, the industrially established HVOF coating process was adapted to use a liquid suspension of commercially available nano-particles (titania- $\mathrm{TiO}_{2}$, and hexagonal boron nitride-h-BN) as feedstock to produce nanostructured suspension $\mathrm{HVOF} \mathrm{TiO}_{2} / \mathrm{h}-\mathrm{BN}$ coatings for the first time on stainless steel. Results indicate that agglomerates in the nano-feedstock can be dispersed by $\mathrm{h}-\mathrm{BN}$ due to poor mutual wettability between $\mathrm{h}-\mathrm{BN}$ and molten $\mathrm{TiO}_{2}$. It also inhibits the anatase-to-rutile transformation of $\mathrm{TiO}_{2}$ during coating deposition by inhibiting sintering of $\mathrm{TiO}_{2}$ in the HVOF flame. The resultant coating becomes superhydrophobic when the addition of $\mathrm{h}-\mathrm{BN}$ reaches $10 \mathrm{wt} \%$ due to the presence of hierarchical nano-texture on the surface. The superhydrophobicity (contact angle of $163-170^{\circ}$ ) is maintained over a long period of time ( $>13$ months, test still ongoing) and remains stable after exposure to light and tape test. A potential route for industrial preparation of robust water-repellent coatings is therefore highlighted by the study.

that a rough surface promotes either hydrophilicity or hydrophobicity, while the Cassie-Baxter model shows that a gaseous layer can be trapped in the cavities of a rough surface, making it possible to obtain a high water contact angle.

A number of fabrication techniques have been reported for preparing superhydrophobic surfaces including: templating, lithography, phase separation, etching, sol-gel, electrospinning and vapour deposition. Surfaces formed by these processes can be classified into three categories:

(1) Polymeric surfaces with designed micro/nano structure; ;,4

(2) Inorganic or textile rough surfaces modified by low surface energy materials, such as hydrocarbons, silicones, fluorocarbons; $;, 5-7$

(3) Inorganic surfaces with hierarchical surface roughness. ${ }^{13,14}$

Currently, most coatings developed belong to the first two types, e.g. organic materials with low surface energy are applied to achieve superhydrophobicity. However, the use of polymeric and organic materials on water-repellent surfaces has limitations in engineering applications due to their inherent instability. Degradation can be accelerated by living organisms, heat, light (e.g. UV exposure), chemistry or other factors. Moreover, the lack of mechanical strength and heat resistance is a significant disadvantage, preventing the use of these coatings in high temperature and/or harsh environments. ${ }^{14}$ Inorganic materials are therefore important for the
${ }^{a}$ National Centre for Advanced Tribology at Southampton (nCATS), Engineering Sciences, University of Southampton, Southampton, SO17 1BJ, UK. E-mail: wangs@ soton.ac.uk

${ }^{b}$ University College London, Dept of Chemistry, 20 Gordon Street, London, WC1H OAJ, $U K$

${ }^{c}$ TWI Limited, Cambridge, CB21 6AL, UK

$\dagger$ Electronic supplementary information (ESI) available: XPS analysis spectra and sliding wear test results. See DOI: 10.1039/c5ta02130h 
development of high quality coatings with long-term superhydrophobicity.

Ceramics are an important category of readily available inorganic materials, and can be prepared relatively easily and inexpensively with good mechanical strength, heat and corrosion resistance. Ceramics are rarely used for water-repelling surfaces due to their intrinsically hydrophilic nature, resulting from their high surface energy due to a large number of polar sites on their surfaces, ${ }^{15,16}$ but the possibility of achieving superhydrophobicity by roughening the surface of hydrophilic materials has been demonstrated by recent publications. For example, a leaf-like $\mathrm{Y}_{2} \mathrm{O}_{3}$ superhydrophobic surface, synthesised on a porous fibre-board template, was reported by Jia et $a .^{13}$ and nanostructured boron nitride with various morphologies has been produced via thermal-CVD, boron-ink, and plasma-enhanced pulsed-laser deposition (PLD) processes. ${ }^{17-19}$ As no chemical modification or treatment was applied to these surfaces, their water-repellent behaviour was ascribed to typographical factors, with air reservoirs playing a major role in improving the water contact angle. ${ }^{13}$ While these ceramic superhydrophobic surfaces have good mechanical properties and excellent thermal and chemical stability, the methods used for depositing these coatings require long deposition times, are expensive, and are not robust enough for industrial scale-up.

High Velocity Oxy-Fuel (HVOF) spraying is a common used industrial thermal spray coating process. HVOF softens or partially melts powder feedstocks within the size range of typically 15-63 $\mu \mathrm{m}$, although HVOF systems to deposit finer powders $(<10 \mu \mathrm{m})$ are now also available, ${ }^{20}$ and deposits a coating by projecting the particles at high velocity onto a surface. HVOF is characterized by relatively low flame temperature (up to $3200{ }^{\circ} \mathrm{C}$ ) and high particle velocities (up to $1000 \mathrm{~m}$ $\mathrm{s}^{-1}$ ), both of which are crucial for preserving the original feedstock morphology and achieving high bond strength between coating and substrate. ${ }^{20}$ However, attempts to deposit nanofeatured coatings using HVOF have been hampered by the need to obtain sufficient particle softening to successfully form a coating, whilst still retaining the nano-structure within the original powder particles. $^{21}$ These attempts were aimed at obtaining coatings with novel tribological properties, rather than superhydrophobicity. In conventional powder feeding, a reduction of the particle size below $5 \mu \mathrm{m}$ requires specialised powder feeding methods due to the poor flowability of such feedstocks, which results from strong agglomeration between particles. ${ }^{22}$ However, in the last decade a modification of the HVOF technology, suspension HVOF (also known as highvelocity suspension flame spraying), has been developed to feed ultra-fine materials $(<5 \mu \mathrm{m})$ suspended in a liquid phase. This provides good flowability of nano or sub-micron sized powders and thus enables the manufacture of nanostructured coatings via thermal spraying, presenting an opportunity to design and fabricate complex coating architectures with controlled hierarchical microstructures. ${ }^{23}$

In this work, suspension HVOF was used to deposit ceramic coatings. To achieve the micro- and nano-scaled hierarchical structure required for hydrophobicity as well as adequate coating adhesion, a combination of two ceramics with different melting temperatures were selected. A commercially available $\mathrm{TiO}_{2}-\mathrm{P} 25$ nanopowder was used as the dominant coating component, and a plate-like h-BN powder was selected as a coating additive due to its interesting wettability, ${ }^{19}$ to produce a nanostructured composite of $\mathrm{TiO}_{2} / \mathrm{h}$ - $\mathrm{BN}$ coatings. $\mathrm{TiO}_{2}$ is a nontoxic, inexpensive ceramic material with excellent mechanical properties and chemical stability. ${ }^{24}$ It has a low melting point of ca. $1800{ }^{\circ} \mathrm{C}$, allowing good melting in the flame and hence good bond strength. h-BN has a melting point of $3100{ }^{\circ} \mathrm{C}$ and can be largely unaffected by the suspension HVOF flame conditions. The effects of different quantities of h-BN on the structure and wettability of $\mathrm{TiO}_{2} / \mathrm{h}$-BN coatings have been investigated in this work and are discussed in detail below.

\section{Experimental details}

\section{Suspension preparation}

A commercial $\mathrm{TiO}_{2}$ nanopowder (Aeroxide ${ }^{\circledR}$ P25, DegussaEvonik, Germany) was used as part of the feedstock. The specific surface area (SSA BET) is $c a .50 \mathrm{~m}^{2} \mathrm{~g}^{-1}$, which remains essentially unchanged under thermal treatment up to $500{ }^{\circ} \mathrm{C}$, but reduces to $c a .40 \mathrm{~m}^{2} \mathrm{~g}^{-1}$ at $600{ }^{\circ} \mathrm{C}$ for which temperature corresponds to the transformation from anatase to rutile phases. ${ }^{25}$ The h-BN powder was purchased from Shanghai ST-Nano Science \& Technology Co. Ltd, Shanghai, China. The suspension consisted of $5 \mathrm{wt} \%$ solid powders and $95 \%$ solvents. Four solid powders were prepared: $100 \% \mathrm{TiO}_{2} ; 95 \% \mathrm{TiO}_{2}+5 \% \mathrm{~h}-\mathrm{BN} ; 90 \%$ $\mathrm{TiO}_{2}+10 \%$ h-BN; $85 \% \mathrm{TiO}_{2}+15 \%$ h-BN (wt $\%$ ). The solvents were a mixture of $\mathrm{H}_{2} \mathrm{O}$ and isopropanol in the volume ratio of $3: 1$ used as the carrier. A dispersant, polyethylene glycol (PEG) with molecular weight of 4000 , was added to the suspension to stabilize the nanoparticles. The samples labelled as S-H-0, S-H5, S-H-10 and S-H-15 correspond to the coatings prepared using the $\mathrm{TiO}_{2}$ solid powders with different h-BN mixtures of $0,5,10$, $15 \mathrm{wt} \%$ respectively.

\section{Coating deposition}

AISI Grade 304 stainless steel with dimensions of $25 \mathrm{~mm} \times 25$ $\mathrm{mm} \times 1.5 \mathrm{~mm}$ was used as a substrate. All of the substrates were grit blasted with 100 mesh fused alumina abrasive prior to HVOF spraying. The coating deposition process was carried out using a UTP Top Gun ${ }^{\circledR}$ torch with a $22 \mathrm{~mm}$ long combustion chamber and a $135 \mathrm{~mm}$ long expansion nozzle mounted on an OTC AII-V20 robot. An ISCO® 260D syringe pump was used to control the suspension feed rate. Suspension was fed radially into the flame (Fig. 1a). Compared with conventional thermal spraying, suspension thermal spraying typically needs much shorter spray distances due to the significantly lower feedstock particle momentum and thermal inertia. Thus the heat flux transferred from flame to substrate is at least one order of magnitude higher than conventional spray at similar powder feed rates. ${ }^{26}$ Hence, water cooling was used to prevent overheating and/or distortion of the substrates by keeping them at a constant temperature of $55{ }^{\circ} \mathrm{C}$ even though the surrounding rings were of a significantly higher temperature (Fig. 1b and c). 
Suspension HVOF trials were performed using hydrogen as the fuel gas; other spray parameters are provided in Table 1. The spray route of the gun on the coating surface is shown in Fig. S1 of the ESI. $\dagger$

5

\section{Suspension and coating characterization}

The size distribution of the suspensions was characterised by Zeta-APS (Matec Applied Sciences, USA). The suspensions were magnetically stirred for $20 \mathrm{~min}$ and then ultrasonically dispersed for $10 \mathrm{~min}$ to break up or avoid large agglomerates before testing. The surface and cross section morphologies were observed using a scanning electron microscope (SEM) (JEOL JSM 6500F, Japan). Stereoscopic images of the as-sprayed coating surfaces were acquired through MeX software (Alicona InfiniteFocus SL) using SEM images taken at 3 different angles $\left(-5^{\circ}, 0^{\circ}, 5^{\circ}\right)$. Cross sections of the coatings were cold-mounted in resin, ground with $\mathrm{SiC}$ grit papers in stages from 120 mesh down to 4000 mesh and finally polished with $0.4 \mu \mathrm{m} \mathrm{Al}_{2} \mathrm{O}_{3}$ slurry. To measure the coating thickness, at least five readings were taken in different places. Fractured cross sections were prepared by breaking the sample in liquid nitrogen.

The crystalline phases of the coatings were measured by Xray diffraction (XRD) using a Bruker D2 PHASER diffractometer in the reflection mode with $\mathrm{Cu}-\mathrm{K} \alpha$ radiation $(\lambda=0.154 \mathrm{~nm})$. The scan step was $0.02^{\circ}$ with a step time of $0.5 \mathrm{~s}$ in the $10-80^{\circ} 2 \theta$ range. The volume percentage of rutile is determined as follows: ${ }^{27}$

$$
C_{\mathrm{R}}=\frac{13 I_{\mathrm{R}}}{8 I_{\mathrm{A}}+13 I_{\mathrm{R}}}
$$

where $I_{\mathrm{A}}$ and $I_{\mathrm{R}}$ are the X-ray intensities of the anatase (101) and the rutile (110) peaks respectively. X-ray photoelectron spectrometry (XPS) was carried out on a Thermo Scientific Theta Probe (Thermo Scientific, East Grinstead, UK), using a monochromatic Al-K $\alpha$ X-ray source operated at $105 \mathrm{~W}$. Survey spectra were collected at $200 \mathrm{eV}$ pass energy and high resolution spectra were collected at $40 \mathrm{eV}$ pass energy. Dual ion charge neutralisation was used throughout the analysis.
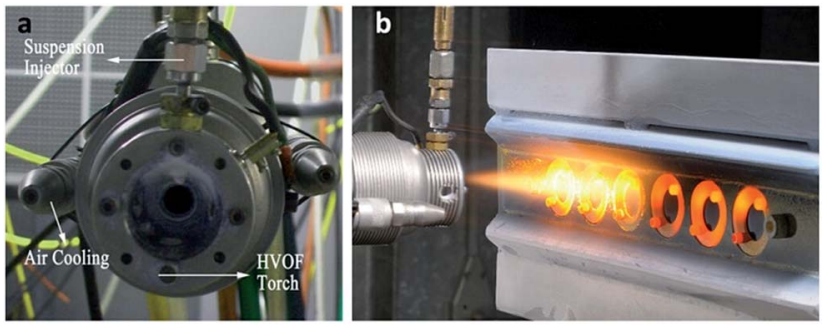

c

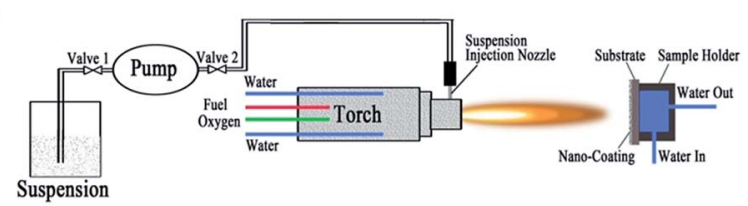

Fig. 1 Suspension HVOF system set-up (a), suspension HVOF spray process (b), and schematic of suspension HVOF system for nanostructured coatings (c).

Table 1 Main suspension HVOF spraying parameters

Pass spacing, mm 2

Torch linear velocity, $\mathrm{mm} \mathrm{s}^{-1}$

Torch cooling system

Combustion chamber length, $\mathrm{mm}$

Profile of suspension nozzle, $\mathrm{mm}$

Hydrogen flow rate, slpm

Oxygen flow rate, slpm

Suspension feed rate, $\mathrm{ml} \mathrm{min}^{-1}$

Spray distance, $\mathrm{mm}$

Number of passes

A pull-off adhesion test based on ASTM C633 was used to determine the adhesion strength of the coatings. Araldite AV 170 epoxy was used as the adhesive. The test was performed with a cure time of $1 \mathrm{~h}$, cure temperature of $150{ }^{\circ} \mathrm{C}$ and with adhesion stud diameter of $18 \mathrm{~mm}$, which was selected due to the small size of samples to decrease shear.

The water contact angle was measured at ambient temperature using a Drop Shape Analysis system (DSA100, Germany) with a computer-controlled liquid dispensing system. To examine the effect of light irradiation on the coating wettability, a $300 \mathrm{~W}$ Xeon lamp (PLS-SXE 300, Beijing TrustTech) was used. Both UV and IR cut-off filters (UVCUT 400 and IR filter, Beijing TrustTech) were equipped to remove all incoming wavelengths shorter than $390 \mathrm{~nm}$ and higher than $800 \mathrm{~nm}$ to ensure irradiation with visible light only. The light intensity

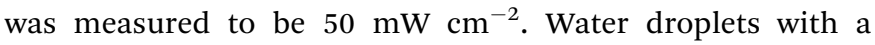
volume of $8 \mu \mathrm{l}$ were used to measure the static water contact angle. The average value of five measurements at different positions on the as-deposited coatings was used as the final contact angle.

The robustness of the coating and the durability of the surface was studied using an adhesive tape test based on ISO 2409:2003, using a transparent pressure sensitive tape (adhesion of this tape to steel is approximately $4.3 \mathrm{~N} \mathrm{~cm}^{-1}$ ). An eraser on the end of a pencil was used to rub the tape firmly to ensure good contact with the coating. Then the tape was removed within $90 \mathrm{~s}$ of application by seizing the free end and rapidly (not jerking) it back upon itself at as close to an angle of $180^{\circ}$ as possible. A sliding wear test was also used to check for wettability changes under severe damage conditions (Fig. S4 of the ESI†).

\section{Results and discussion}

Feedstock characteristics

The $\mathrm{TiO}_{2}$ nanoparticles exhibited a spherical shape with average diameter of about $25 \mathrm{~nm}$ (Fig. 2a). The h-BN nanoparticles were plate-like with a size of 130-200 nm (Fig. 2b). The average size of particles/agglomerates in suspensions S-H-0, S-H-5, S-H-10 and S-H-15 were $35 \mathrm{~nm}, 49 \mathrm{~nm}, 42 \mathrm{~nm}$ and $57 \mathrm{~nm}$, respectively (Fig. 2c), with all suspensions exhibiting a very narrow particle size range. A very small amount of agglomeration was observed in the range between $190 \mathrm{~nm}$ and $390 \mathrm{~nm}$. With increasing h-BN content, the secondary peak moves toward to the right (Fig. 2c)
2

600

Water cooling

135

0.3 /orifice

788

264

20

100

20 
indicating increasing agglomerate sizes, which is attributed to the increased amount of large h-BN particle size.

A narrow feedstock size distribution and small agglomerate size are crucial for the stabilization of the suspension, as sedimentation velocity is directly proportional to the particle radius squared. In the suspension (e.g. S-H-10 with $90 \mathrm{wt} \% \mathrm{TiO}_{2}+10$ wt $\%$ h-BN) no sedimentation was observed after 2 hours (Fig. 2d), demonstrating its good stability. The feedstock particle size and distribution are also important parameters influencing the particle thermal history. Smaller particles can be accelerated, heated but lose momentum quickly in the flame due to their lower mass, or may re-solidify before impact, both of which lead to weak bonding. Coarser particles on the other hand, can result in the presence of non-melted particles and produce porous coatings, as reported by Bolelli et al. ${ }^{28}$ Thus the ability to make $\mathrm{TiO}_{2}$ suspensions with different amounts of h$\mathrm{BN}$ and a narrow size distribution (Fig. 2c) can be beneficial to achieve uniform heating and acceleration of in-flight feedstock, leading to high density coatings with good adhesion and higher cohesive strength.

\section{Coating formation mechanism}

Thermally sprayed coatings are formed by the build-up of individual "splats" on a substrate. To study the coating formation mechanism, a single coating track was deposited on the grit-blasted 304 stainless steel substrate. Three typical features were observed: well-molten splats (micro-sized irregular shapes with smooth surfaces), re-solidified/partially-molten splats (spherical or half-spherical features) and agglomerated particles (nanosized particle clusters) (Fig. 3a-c), in accordance with the
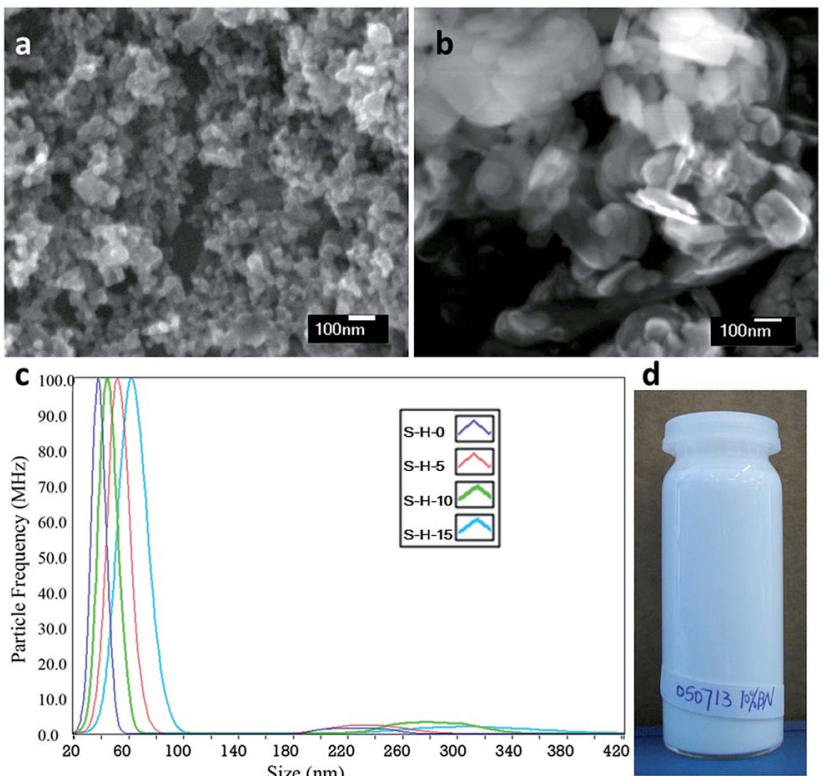

Fig. 2 SEM images of nanostructured $\mathrm{TiO}_{2}$ particles (a) and nanostructured $\mathrm{h}-\mathrm{BN}$ particles (b), size distribution of suspensions with different amounts of $h-B N$ ( 5 wt\% solid content, $95 \mathrm{wt} \%$ liquid content) (c), and digital image of sedimentation test of suspension ( $\mathrm{S}-\mathrm{H}-10)$ after 2 hours (d). published results. ${ }^{29-32}$ Well-molten splats deposited from $\mathrm{TiO}_{2}$ suspension with solid content of $5 \mathrm{wt} \%$ have diameters up to 5 $\mu \mathrm{m}$ (Fig. 3a); significantly smaller than those from conventional thermal spraying processes $(30-80 \mu \mathrm{m}) .{ }^{33}$ Good contact between splats and substrate is a prerequisite for good coating adhesion. ${ }^{34}$ The well-molten splats in Fig. $3 \mathrm{~b}$ demonstrate a very thin structure, which adapt well to the substrate irregularities and hence promote better contact. Furthermore, no visible cracks were observed although the splat is being impacted onto the target substrate by a hypersonic speed gas jet. Agglomerated nanoparticles and re-solidified spherical particles are distributed randomly across the substrate surface (Fig. 3c).

The generation of these nano-sized or micro-sized features has been widely discussed in the literature. ${ }^{31,34-36}$ They are mainly caused by differing particle trajectories in the flame (Fig. 3d) and by various droplet sizes being formed from the disintegration of primary droplets of suspension in the flame. The molten particles have sufficient momentum to spread out in the form of splats when they impinge on the substrate. Spherical or half-spherical particles are also present, and can be ascribed to either inadequate heating or rapid cooling. In the first instance feedstock may be only partially melted, leading to a solid core with a molten exterior. The second mechanism occurs when the feedstock is completely melted and then partially/fully re-solidifies before reaching the substrate. In either case, the solid part (core for the first case and shell for the second case) resists deformation and thus reduces or prevents the spreading of the droplet. Smaller agglomerated particles mainly travel in the secondary flame zone - a significantly cooler region of the flame, due to the lack of kinetic energy from injection to feed into the core of the flame. They are therefore able to keep their original nanostructure when impacting onto the substrate surface. The distribution of particles inside the flame jet is difficult to observe without shadowgraphy, but random distribution of single particles can be clearly seen near the edge of the flame in the digital image shown in Fig. 3e.
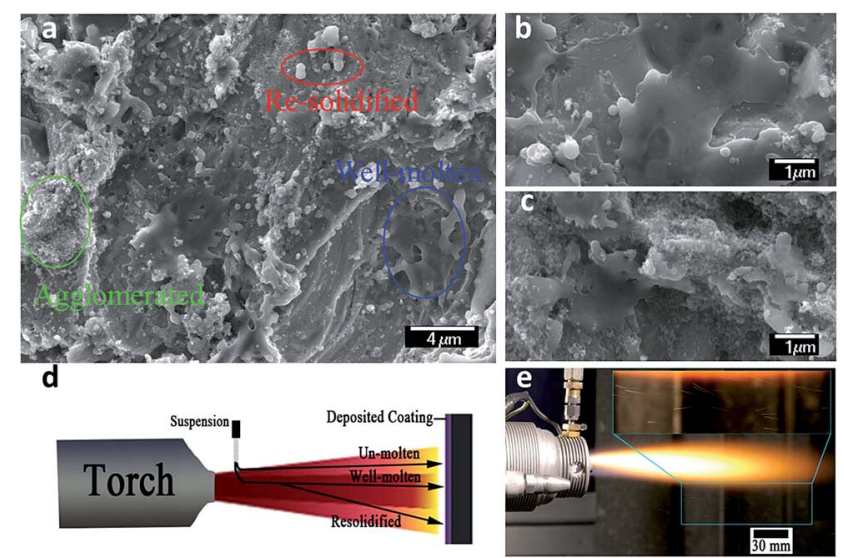

Fig. 3 SEM images of deposited splats of suspension S-0 at low magnification (a), region of molten particles at high magnification (b), region of agglomerate particles at high magnification (c), schematic diagram of particle trajectories within the flame (d), and digital image of the flame during suspension HVOF deposition process (e). 


\section{Morphologies and phases of deposited coatings}

The surface morphologies of the suspension HVOF sprayed $\mathrm{TiO}_{2}$ coatings as characterized by SEM reveal "protuberancelike" features scattered throughout the coating at low magnification (Fig. 4a, c, e and g). At higher magnifications (Fig. 4b, d, f and $\mathrm{h}$ ) it can be seen that these features are composed of different levels of hierarchical micro/nano-structures. The surface of S-H-0 coating (Fig. 4b) is mainly composed of wellmolten $\mathrm{TiO}_{2}$ splats with small amounts of non-melted $\mathrm{TiO}_{2}$ nanoparticles adhered onto the splats. With increasing h-BN content, higher levels of nanoparticles that have retained their original morphological features can be observed. The surfaces of coatings S-H-10 and S-H-15 are mainly covered by non-molten particles. Similar "protuberance-like" features have been reported in the literature, ${ }^{37}$ and their formation is thought be due to the different agglomeration/sintering rates of the feedstock within the flame during deposition. Smaller particles possess lower inertia, and instead of impacting at high velocity they tend to travel laterally along the substrate surface, following the radially deflecting gas jet at the stagnation point just above the substrate. This favours their attachment to prominent asperities formed by previously deposited larger particles, as confirmed by numerical simulated results. ${ }^{38}$ It has been reported that h-BN has poor wettability in many metallic and non-metallic melts. ${ }^{39}$ So it is likely that h-BN acts as a dispersant in the flame at the sintering stage, restricting the agglomeration of the $\mathrm{TiO}_{2}$ nanoparticles, resulting in a higher number of small particles which can attach themselves to protuberances on the coating surface.

The average roughness value $\left(R_{\mathrm{a}}\right)$ is the most commonly used amplitude parameter to characterize random solid surface roughness. $R_{\mathrm{a}}$ is the arithmetic mean of the absolute departures of the roughness profile peaks/troughs from the mean line. Since significantly different rough surface profiles can have the same $R_{\mathrm{a}}$, two additional parameters namely skewness $\left(R_{\mathrm{sk}}\right)$ and kurtosis $\left(R_{\mathrm{ku}}\right)$ are used to characterise the surface topography. $R_{\text {sk }}$ is a non-dimensional measure of the asymmetry of surface peaks/troughs around the mean line. The surface is dominated by 'hills' (peaks) when it is positive, and 'valleys' (troughs) when it is negative. $R_{\mathrm{ku}}$ is the non-dimensional measure of the sharpness of the peaks. A surface with high $R_{\mathrm{ku}}$ is "spiky", whilst a surface with low kurtosis has a more blunted peak/trough topography. ${ }^{40}$ Three-dimensional images of the pure $\mathrm{TiO}_{2}$ coating (S-H-0) and the $\mathrm{TiO}_{2}$ coating made with suspension containing 15 wt $\%$ h-BN (S-H-15) are shown in Fig. 5a and b, with their roughness parameters listed in Fig. 5c. Both of the two coatings have similar $R_{\mathrm{a}}(c a .2 .7 \mu \mathrm{m})$ and their surface features are nearly symmetrical ( $R_{\text {sk }}$ values close to zero), but their $R_{\mathrm{ku}}$ values are different. $R_{\mathrm{ku}}$ is nearly 3 for S-H-0 and only 2.3 for $\mathrm{S}-\mathrm{H}-15$. The topography of $\mathrm{S}-\mathrm{H}-0$ has sharp peaks and valleys (Fig. 5a). So the addition of h-BN not only changes the coating surface microstructure but also blunts its topography, in agreement with previous observations (Fig. 4).

In order to further study the effect of h-BN addition on the coating structure, coatings $\mathrm{S}-\mathrm{H}-0$ and $\mathrm{S}-\mathrm{H}-15$ were cross sectioned and examined in SEM (Fig. 6). Both coatings have a
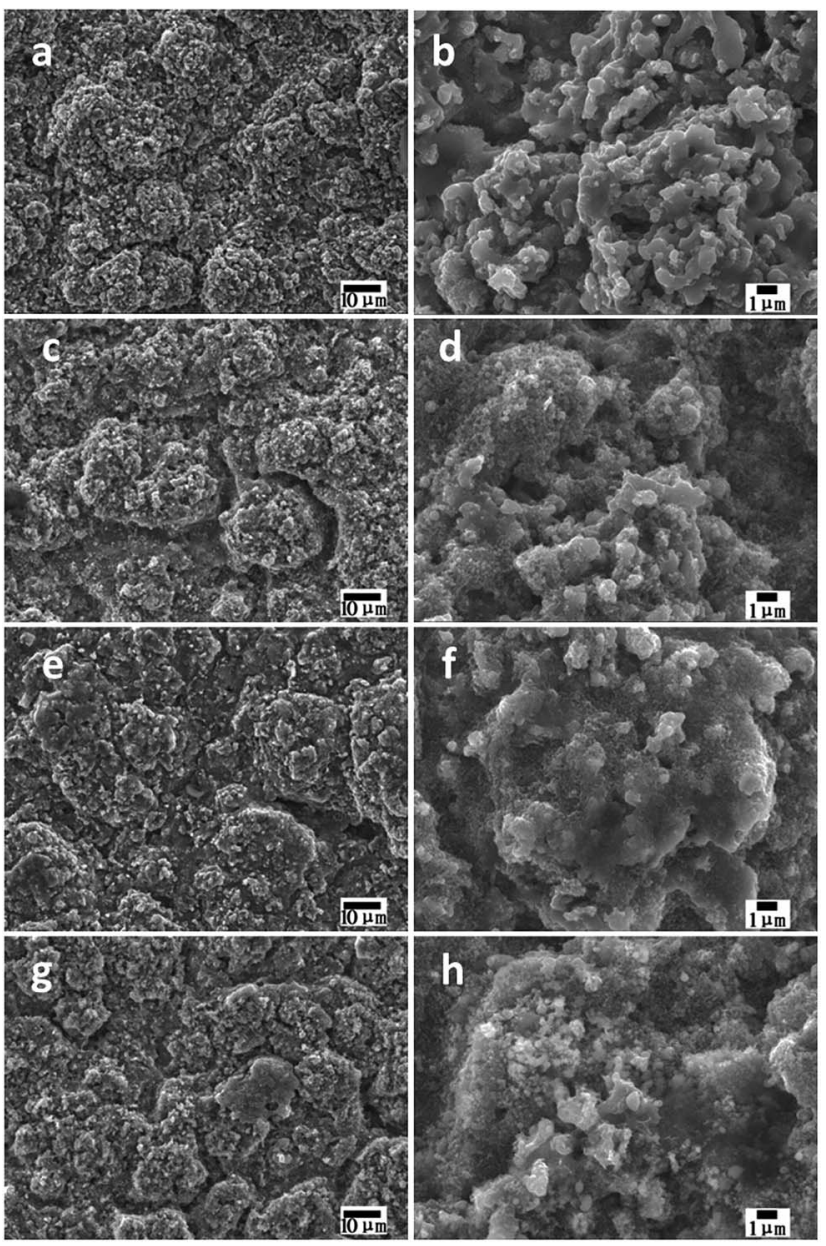

Fig. 4 Surface morphologies of S-H-O (a and b), S-H-5 (c and d), S-H10 (e and $\mathrm{f}$ ) and $\mathrm{S}-\mathrm{H}-15$ ( $\mathrm{g}$ and $\mathrm{h}$ ) coatings.

dense structure without visible voids or cracks (Fig. 6a and b). They exhibit the typical "bimodal microstructure" characteristic of suspension thermal sprayed coatings and are composed of
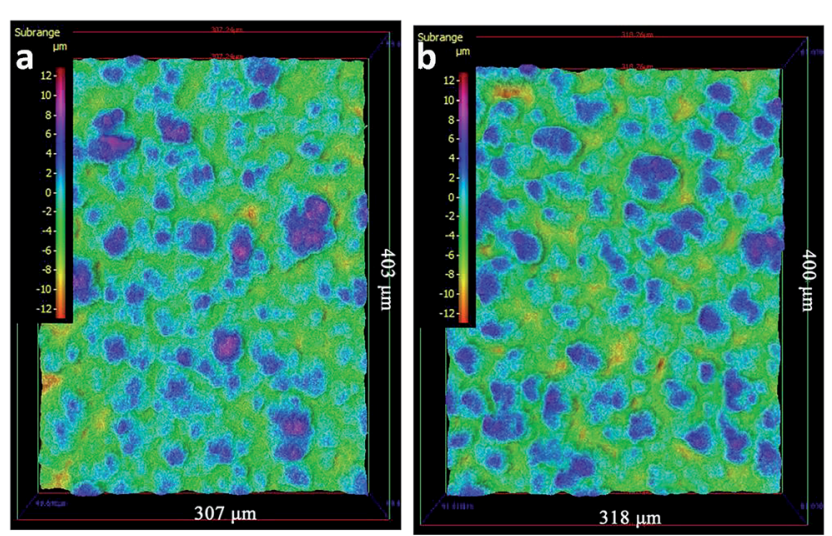

\begin{tabular}{llll} 
C Coating & $\mathrm{Ra}, \mu \mathrm{m}$ & $\mathrm{Rsk}, \mu \mathrm{m}$ & $\mathrm{Rku}, \mu \mathrm{m}$ \\
\hline $\mathrm{S}-\mathrm{H}-0$ & $2.78 \pm 0.21$ & $0.05 \pm 0.17$ & $2.93 \pm 0.15$ \\
$\mathrm{~S}-\mathrm{H}-15$ & $2.70 \pm 0.40$ & $-0.05 \pm 0.15$ & $2.33 \pm 0.06$ \\
\hline
\end{tabular}

Fig. 5 Stereoscopic images of suspension HVOF sprayed coatings: S$\mathrm{H}-\mathrm{O}$ (a), S-H-15 (b), and surface roughness values (c). 
1 well-molten, partially-molten and agglomerated zones (Fig. 6c). A Raman microscopy analysis performed by Bannier et al. has confirmed that the well-molten zone is mostly rutile while the agglomerated zone is mainly anatase, for thermal sprayed $\mathrm{TiO}_{2}$ coatings. ${ }^{41}$ Compared with the pure $\mathrm{TiO}_{2}$ coating deposited using the same parameters, the composite coating with $15 \mathrm{wt} \%$ h-BN has a homogeneous distribution and a refined microstructure. In addition, agglomerated zones containing h-BN are observed in the coating. The thickness of the S-H-0 coating is $c a$. $45 \mu \mathrm{m}$ while the $\mathrm{S}-\mathrm{H}-15$ coating is $c a .32 \mu \mathrm{m}$ (insets in Fig. $6 \mathrm{a}$ and b). Considering all the other parameters such as suspension feed rate, coated area and spray pattern were unchanged, this could be attributed to different aerodynamic behaviour of $\mathrm{TiO}_{2}$ and/or h-BN sintered particles/splats via different particle morphology and size. As described above, h-BN can restrict the aggregation of $\mathrm{TiO}_{2}$ particles, leading to the formation of smaller agglomerates or even discrete nanoparticles. This could lead to two consequences: (1) the high speed spray may blow away any small particles not strongly adhering to the substrate, and (2) smaller sintered particles/splats fail to enter the hottest part of the flame and are not fully melted, leading to a lower deposition rate. ${ }^{\mathbf{2 9}, \mathbf{3 0}}$

The h-BN particles are embedded throughout the coating but appear more concentrated in the agglomerated zones (Fig. 6c). No typical conventional HVOF lamellae are observed in the suspension HVOF coatings. Half-melted and un-melted zones are generally surrounded by well-melted zones. The presence of these dense nano-zones embedded in the coating structure has been reported to arrest and deflect crack growth, which can improve the mechanical strength of the coating. ${ }^{37}$ A fractured sample was prepared to further study of the coating microstructure in cross section (Fig. 6d). The distribution of plate-like h-BN particles throughout the coating can be clearly seen in the fracture face (blue circles); they maintain their original morphology due to their high melting temperature. Individual h-BN sheets or small groups are attached on micro-sized $\mathrm{TiO}_{2}$
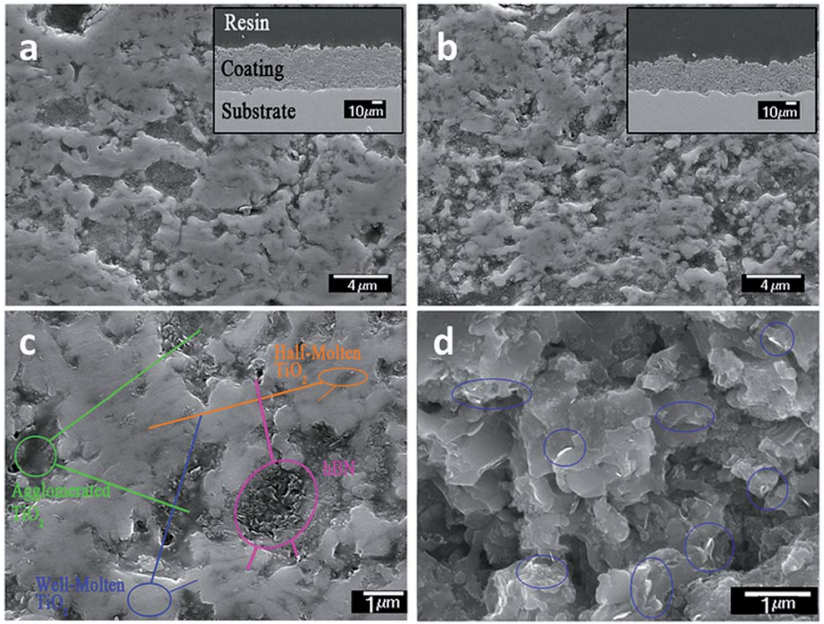

Fig. 6 Cross-sectional structures of suspension HVOF sprayed coatings: $\mathrm{S}-\mathrm{H}-0$ at low magnification (a), and $\mathrm{S}-\mathrm{H}-15$ at low magnification (b), at high magnification (c) and fractured cross-sectional surface (d). sintered splats or dispersed among them. Although the coating cohesion may be strengthened by the h-BN interlocking among the splats, the adhesion to the substrate may be not as strong as molten zones. Indeed, pull-off adhesion results showed that SH-0 had an adhesion strength of 51.7 $\pm 10.4 \mathrm{MPa}$ compared with $45.5 \pm 8.6 \mathrm{MPa}$ for S-H-15. The slight decrease of adhesion is probably due to the formation of weak agglomerated zones.

The phase structure of the P25 powder was identified using $\mathrm{X}$-ray diffraction, the standard JCPDS patterns being PDF\#211272 for anatase and PDF\#21-1276 for rutile. Both anatase and rutile were detected (Fig. 7) and the volume percentage of rutile is $19 \%$. The as-received h-BN powders were analysed using JCPDS standard pattern PDF\#34-0421, which showed hexagonal structure of BN phase. A typical h-BN peak of (002) can be observed for the coatings with $10 \mathrm{wt} \% \mathrm{~h}-\mathrm{BN}$ addition and enhanced with the h-BN addition (15 wt\%). No other phases besides $\mathrm{TiO}_{2}$ and h-BN were detectable in the coatings. Compared with feedstock (P25), all the coatings show much high XRD peaks of rutile (e.g. $\left.(110)_{\mathrm{R}}\right)$. The anatase-to-rutile transformation is due to heat exchange between the flame and feedstock during coating deposition process. With the h-BN additions in feedstock increase from 0 to $15 \mathrm{wt} \%$, rutile contents in the coatings decrease from $70 \%$ to $61 \%$. It is clear that the addition of h-BN restrains the anatase to rutile transformation as well as sintering, since these two behaviours are interrelated $^{42}$ (Fig. 6 and 7). The thermal conductivity of BN is ca. $33.0 \mathrm{~W} \mathrm{mK}{ }^{-1},{ }^{43}$ compared with 10.4 and $180.0 \mathrm{~W} \mathrm{mK}^{-1}$ for rutile and anatase $\mathrm{TiO}_{2}$, respectively. ${ }^{44}$ This phase transformation inhibition can be explained by non-optimised particle entrainment and less melting resulted from the formation of smaller sintered agglomerates with increasing $\mathrm{h}$ BN addition. Needle-like hydroxyapatite, which also has lower thermal conductivity, has been reported to have a similar inhibition effect on the $\mathrm{TiO}_{2}$ phase transformation. ${ }^{45}$ The XRD results further prove that the addition of h-BN can decrease the degree of melting, preserving the beneficial feedstock nanostructure.

To further characterize the chemical state of the surface, $\mathrm{X}$ ray photoelectron spectroscopy (XPS) analysis was carried out on S-H-0 and S-H-15 surfaces (annotated survey spectrums in Fig. $\mathrm{S} 2, \uparrow$ the atomic fractions of the elements are presented in Table S1, $\uparrow$ together with high-resolution spectra of the Ti 2p, O 1s and $\mathrm{B} 1 \mathrm{~s}$ regions in Fig. $\mathrm{S} 3$, from ESI $\dagger$ ). XPS survey spectrum for S-H-0 identifies $\mathrm{O} 1 \mathrm{~s}$, Ti $1 \mathrm{~s}$ and $\mathrm{C}$ 1s peaks, compared with $\mathrm{O}$ 1s, Ti 1s, C 1s, B 1s and $\mathrm{N} 1 \mathrm{~s}$ peaks for $\mathrm{S}-\mathrm{H}-15$. The $\mathrm{C} 1 \mathrm{~s}$ photoelectron peak corresponds to the adventitious carbon on the surface. A lower amount of Ti was found on the S-H-15 coating surface compared with S-H-0 (Table S1 and Fig. S2 $\dagger$ ). It is suspected that S-H-0 surface is richer in $\mathrm{TiO}_{2}$ than $\mathrm{S}-\mathrm{H}-15$. Higher resolution core-level photo-emission spectra of the elements Ti, O and B were displayed in Fig. S3.† For both samples the main doublet peaks are attributed to $\mathrm{TiO}_{2}$. Peaks corresponding to $\mathrm{TiO}_{2-x}$ were also detected on both types of coatings. ${ }^{46}$ The result revealed that there were low-valence titanium cations resulted from deoxidation of $\mathrm{TiO}_{2}$ powders for both coatings and this could be ascribed to the high temperature and reduction environment in the $\mathrm{H}_{2} / \mathrm{O}_{2}$ flame. Similar 


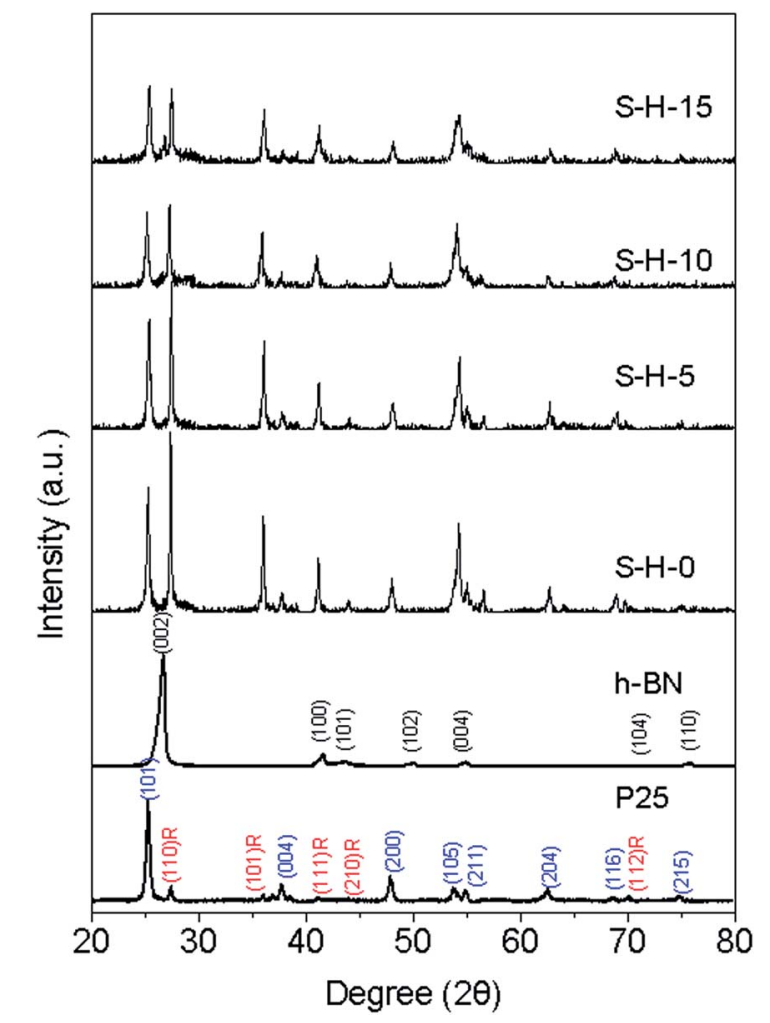

Fig. 7 The $\mathrm{X}$-ray diffraction patterns of feedstocks and suspension $\mathrm{HVOF}$ sprayed $\mathrm{TiO}_{2}$ coatings with different contents of $\mathrm{h}-\mathrm{BN}$ particles.

observations have been published for the plasma spray process. ${ }^{47}$ The $\mathrm{O} 1 \mathrm{~s}$ profile in S-H-0 has a main peak at $530.4 \mathrm{eV}$ ascribed to oxygen atoms of $\mathrm{TiO}_{2}$ and a smaller peak at $532.2 \mathrm{eV}$ corresponding to hydroxyl groups, chemisorbed oxygen and organic oxygen on the surface of the sample, ${ }^{46}$ respectively. A peak observed at $533.2 \mathrm{eV}$ indicating $\mathrm{B}-\mathrm{O}$ bonds of $\mathrm{B}_{2} \mathrm{O}_{3}$, as reported in the literature. ${ }^{48} \mathrm{~A}$ corresponding $\mathrm{B}_{2} \mathrm{O}_{3}$ peak was also obtained in $\mathrm{B}$ 1s spectrum. The lack of $\mathrm{a}_{2} \mathrm{O}_{3}$ peak in the XRD spectrum may be due to its amorphous structure. The $B$ 1s spectrum also exhibited a characteristic peak at binding energy of $190.8 \mathrm{eV}$ which is in good agreement with the reported results of the h-BN phase, ${ }^{\mathbf{1 4}}$ indicating the main species containing $\mathrm{N}$ on the coating surface is in the form of h-BN. This shows decomposition of h-BN during HVOF deposition process, with the ratio of $\mathrm{B}-\mathrm{O}$ to $\mathrm{B}-\mathrm{N}$ bonds at approximately 0.38 . The depth of analysis for XPS is less than $10 \mathrm{~nm}$ which means that photoelectrons will be emitted only from the surface layers. So it can be confirmed that the surface of coating S-H-15 is mostly covered by h-BN with some $\mathrm{B}_{2} \mathrm{O}_{3}$ and $\mathrm{TiO}_{2}$, compared with only $\mathrm{TiO}_{2}$ for coating S-H-0.

\section{Wettability properties}

The wettability of the 304SS substrate and the as-deposited coatings was evaluated by contact angle measurement with de-ioned water (Fig. 8). The change in coating surface wettability with increasing h-BN addition can be clearly observed. The water contact angle of the untreated 304SS surface is approximately $96^{\circ}$, indicating mild hydrophobicity. The water droplet spread completely on the coating S-H-0 surface with water contact angle of approximately $0^{\circ}$, which shows superhydrophilicity, commonly seen in nanostructured surfaces by suspension thermal spraying. With an h-BN addition of $5 \mathrm{wt} \%$, the water contact angle increases to approximately $11^{\circ}$, indicating a hydrophilic surface. At an h-BN addition of $10 \mathrm{wt} \%$, a sharp increase of water contact angle to around $163^{\circ}$ is observed, followed by a further increase to $170^{\circ}$ at $15 \mathrm{wt} \% \mathrm{~h}-\mathrm{BN}$. Living videos for wettability test of both superhydrophilic ( $\mathrm{S} 3-\mathrm{H}-$ 0) and suphydrophobic (S3-H-15) coatings can be found in the cited links. ${ }^{49,50}$ The hysteresis in the contact angle was tested in two different ways: water droplet on tilting plate to test the advancing and receding contact angles and sliding angle test by lifting the plate until the droplet roll off. And results showed that the roll-off angles (hysteresis behaviour) of the deposited superhydrophobic coating varies between 15 to $30^{\circ}$, depending on the way the droplet is put on the surface. As the long-term stability of superhydrophobic surfaces has always been a challenge for their practical applications, ${ }^{51}$ the superhydrophobic coating S-H-15 was stored for 13 months at ambient conditions to check its water-repellence. The influence of light irradiation on its wettability was also studied by putting the sample under simulated visible light for 1.5 hours. The water contact angles are $166^{\circ}$ and $162^{\circ}$ respectively for the two conditions, which demonstrates that the suspension HVOF sprayed $\mathrm{TiO}_{2} / \mathrm{h}-\mathrm{BN}$ coating is able to maintain superhydrophobicity over time and is stable under visible light irradiation (Fig. 8). Tape adhesive tests showed that hardly any particles on the coating surface were peeled off and only loose particles on the edge of the coatings could be seen in Fig. 9. The surface remains superhydrophobic after 6 runs of tape test. Thus it proves that the nanofeatures on the coating top surface have fairly strong cohesion to the coating due to the mechanical interlocking with melted feedstock splats. However, a further sliding wear test showed a reduction of contact angle to $c a .136^{\circ}$ under severe damage conditions (Fig. S4 of the ESI $\dagger$ ).

From XPS analysis, no difference was observed between the carbon contents of the hydrophilic and hydrophobic samples, indicating that none of the surfaces was more prone to carbon contamination. Hence, wettability trends are not due to hydrocarbon contamination of the surface..$^{52}$ In addition to this, only intrinsically hydrophilic species were presented to the coating surface including h-BN, $\mathrm{TiO}_{2}$ and $\mathrm{B}_{2} \mathrm{O}_{3}$. It can be concluded that the different wettability properties of these coatings is a consequence of the particular hierarchical surface topography.

Liquid droplets on rough surfaces are known to exist either in the Wenzel wetting state ${ }^{\mathbf{1 1}}$ or the Cassie-Baxter wetting state. ${ }^{12}$ In the Wenzel state, liquid fills the contours of the rough surface and the apparent contact angle follows:

$$
\cos \theta=r \cos \theta_{\mathrm{y}}
$$

where $r$ is the roughness ratio (defined as the ratio of the true area of surface to its projected area on the horizontal plane, $r>$ 1), $\theta$ and $\theta_{\mathrm{y}}$ are the apparent contact angle and Young contact 


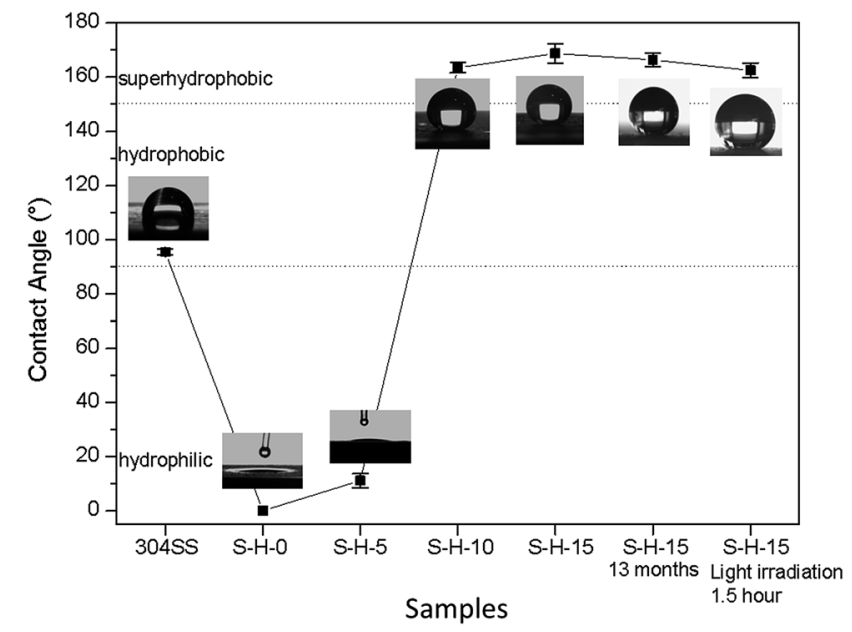

Fig. 8 Static contact angles of 304 SS substrate and suspension HVOF sprayed coatings with different contents of $\mathrm{h}-\mathrm{BN}$ particles.

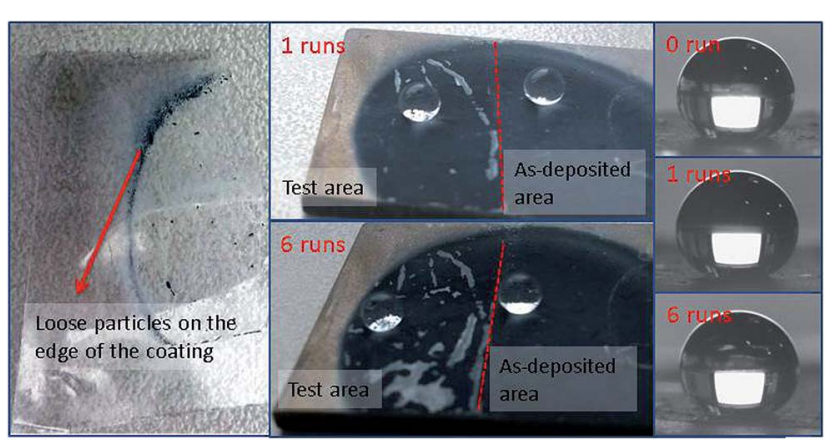

Fig. 9 Tape adhesive test of superhydrophobic surface together with contact angle tests.

angle (for an ideal surface), respectively. This equation predicts that when $\theta_{\mathrm{y}}>90^{\circ}, \theta$ increases toward $180^{\circ}$ with the increase of $r$; however, when $\theta_{\mathrm{y}}<90^{\circ}, \theta$ decreases toward $0^{\circ}$ with the decrease of $r$.

The Wenzel state was extended by Cassie and Baxter to explain more complex conditions, where air is entrapped within a rough surface to enable the liquid to rest on it. According to the Cassie-Baxter model, roughness can reduce apparent surface wettability regardless of the intrinsic wettability behaviour of the actual base material. ${ }^{15}$ Such wetting behaviour is described by eqn (3):

$$
\cos \theta=f_{\mathrm{SL}} \cos \theta_{\mathrm{y}}+f_{\mathrm{LA}} \cos \theta_{\mathrm{A}}
$$

where $f_{\mathrm{SL}}$ and $f_{\mathrm{LA}}$ are the contact area fractions of solid-liquid interface and liquid-air interface in a plane geometrical area to the rough surface respectively, and $\theta_{\mathrm{A}}$ is the contact angle on vapour surface. The contact angle against liquid and air can be considered to be $180^{\circ}\left(\cos \theta_{\mathrm{A}}=-1\right)$ and $f_{\mathrm{SL}}+f_{\mathrm{LA}} \geq 1$. When the drop is small enough where gravity can be neglected and the Laplace pressure is constant between the front (of high curvature) and the rear (of smaller curvature), sagging of the droplet can be neglected and is assumed to be flat, and then $f_{\mathrm{SL}}+f_{\mathrm{LA}}=$ $1 .^{53,54}$ Based on this assumption, eqn (3) reduces to:

$$
\begin{aligned}
\cos \theta=f_{\mathrm{SL}} \cos \theta_{\mathrm{y}}-f_{\mathrm{LA}} & =f_{\mathrm{SL}} \cos \theta_{\mathrm{y}}-\left(1-f_{\mathrm{SL}}\right) \\
& =f_{\mathrm{SL}}\left(\cos \theta_{\mathrm{y}}+1\right)-1
\end{aligned}
$$

Smooth $\mathrm{TiO}_{2}$, h-BN and $\mathrm{B}_{2} \mathrm{O}_{3}$ surfaces all have a water contact angle of approximately $50^{\circ}$ (ref. 14, 55 and 56) and are constitutionally hydrophilic. With increasing surface roughness of the suspension HVOF sprayed $\mathrm{TiO}_{2} / \mathrm{h}$ - $\mathrm{BN}$ coatings, their water contact angles should decrease, based on Wenzel's formulation. However, the measurements show that only S-H0 and S-H-5 have decreased contact angles of $c a .0^{\circ}$ and $c a$. $11^{\circ}$, the other two coatings S-H-10 and S-H-15 show contradictory results with contact angles of $c a .163^{\circ}$ and $c a .170^{\circ}$, respectively. The ratio of the true area of surface to its projected area $-r$ for these coatings has been measured from their stereoscopic images calculated by MeX software, which are approximately 1.60, 1.50, 1.58 and 1.59 for S-H-0, S-H-5, S-H-10 and S-H-15 respectively. Consequently, the apparent contact values are $0^{\circ}, 14^{\circ}, 0^{\circ}$ and $0^{\circ}$ following Wenzel eqn (2). The calculated contact values for coatings S-H-0 and S-H-5 fits well with the tested values but not adaptable for S-H-10 and S-H-15. Thus only the Cassie-Baxter wetting theory can be used for explaining the wetting behaviour, which assumes water bridges the cavities on the surface. The fractions of solid-liquid contact can be calculated to be 0.03 and 0.01 for S-H-10 and S-H-15, respectively (eqn (4)). Eqn (4) reduces to Wenzel's equation when the rough surface is fully covered with water, ${ }^{12}$ and the roughness ratio $(r)$ is indirectly considered in determination of the balance between $f_{\mathrm{sL}}$ and $r$ for the threshold contact angle at which the Wenzel state changes into the Cassie-Baxter state. Therefore, it confirms that the existence of air-liquid-solid interface where the liquid sits on top of the superhydrophobic surfaces.

As discussed above, all these coatings have similar surface roughness (Ra) (Fig. 5) and the sinusoidal protrusions on the surface are of similar size in the micro-scale. It has been demonstrated that multiple roughness scales enhance surface wettability when the basic geometry of the roughness is the same and the presence of a nanostructure on the surface is responsible for the high water contact angle..$^{57,58}$ So the variations in wettability can be attributed to differences in the nanofeatures superimposed on the surface of the micro-sized structures. The top surface of the micro-sized protrusions for pure superhydrophilic $\mathrm{TiO}_{2}$ coating (S-H-0) is mainly composed of smooth well-molten $\mathrm{TiO}_{2}$ splats with diameter $200 \mathrm{~nm}$ to 5 $\mu \mathrm{m}$, and pores constructed by these splats (Fig. 10a). At $5 \mathrm{wt} \%$ $\mathrm{h}-\mathrm{BN}$, the water contact angle increases to $11.1^{\circ}$. This may be due to the presence of scattered nanoparticles on the coating surface and adhered h-BN plates in the molten splats (Fig. 10b), however, they are not packed close enough to suspend water on the coating surface. There is no obvious difference of the wellmolten splats' morphology compared those on coating S-H-0; both exhibit smooth features. Such surface features should allow water droplets to penetrate the coating easily, spreading out over a large area, as also reported in the literature. ${ }^{13}$ 
Both $\mathrm{S}-\mathrm{H}-10$ and $\mathrm{S}-\mathrm{H}-15$ coatings have sharp transition of wettability despite similar structures according to SEM observations (Fig. 4). S-H-15 is used as an example to study the nanostructure difference of superhydrophobic coatings relative to hydrophilic coatings (S-H-0, S-H-5); high magnification images of superhydrophobic coating (S-H-15) morphology are shown in Fig. 10c and d. The surface structure of the micro-sized protrusions comprises two typical features, well-dispersed ultra-fine sintered/agglomerate $\mathrm{TiO}_{2} / \mathrm{h}$-BN particles (Fig. 10c), and melted $\mathrm{TiO}_{2}$ splats with convex folds and vertically inserted h-BN plates (Fig. 10d). The convex folds on the splat surface have a height up to $35 \mathrm{~nm}$ (measured by the green profile), while the vertically inserted h-BN plates on the surface have a height above splat surface of around $20 \mathrm{~nm}$ (as measured by the pink profile). There are also h-BN plate and thin $\mathrm{TiO}_{2}$ splat adhered areas (as measured by the blue profile), which have bigger peak sizes of around $120 \mathrm{~nm}$. These randomly distributed nano-features on the surface are beneficial to retain the air beneath the water droplets, thus decreasing the wettability, which has also been confirmed by previous publications. ${ }^{59,60} \mathrm{So}$, the superhydrophobicity of $\mathrm{TiO}_{2} / \mathrm{h}$ $\mathrm{BN}$ coatings can be ascribed to the generation of a multi-scale hierarchical rough structure, which enables air pockets to be trapped in the cavities formed by the nano-features on the coating surface, suspending the water droplets (Fig. 10f). The menisci
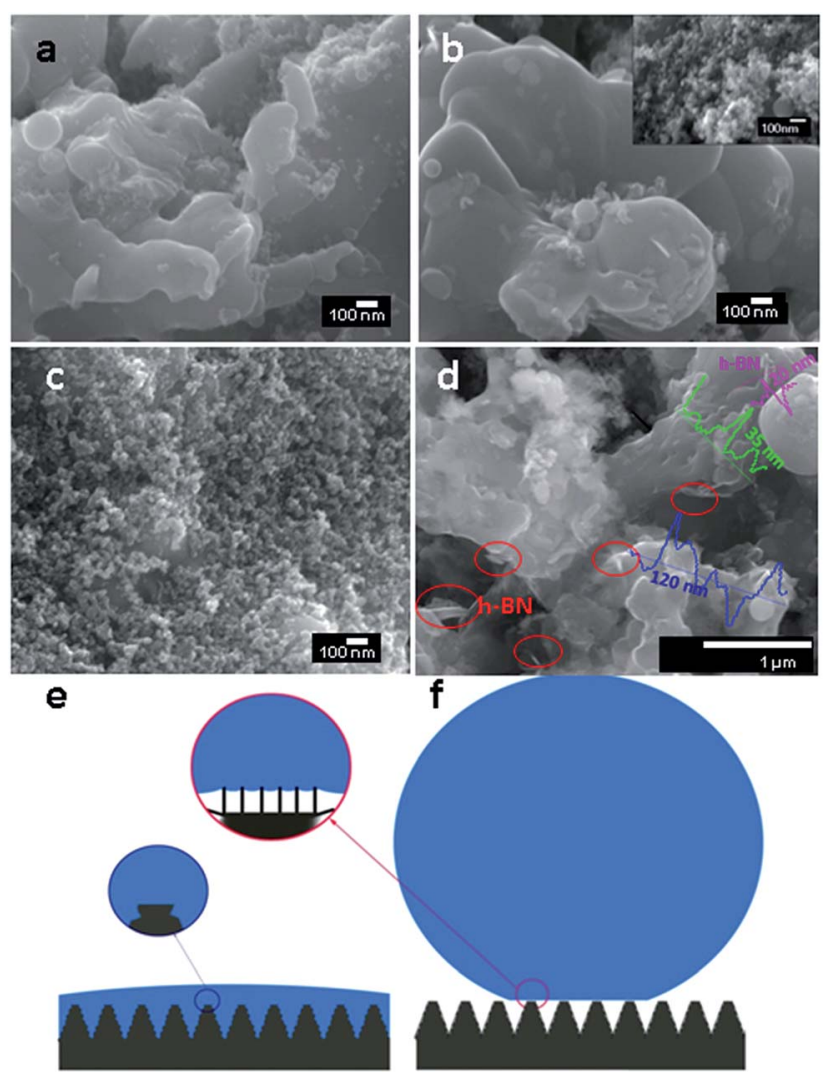

Fig. 10 Structure analysis under high magnifications of suspension HVOF sprayed coatings ( $\mathrm{S}-\mathrm{H}-0$ ) (a), $\mathrm{S}-\mathrm{H}-5$ (b), $\mathrm{S}-\mathrm{H}-15$ of agglomerate region (c) and nano-textured region (d), and schematic illustrations of superhydrophilic surface (e) and superhydrophobic surface (f), air is entrapped underneath water drop on the surface (f, inset). below the droplet between two contact edges are due to the liquid's weight (insert of Fig. 10f), as opposed to the solid-liquid interface (Fig. 10e).

\section{Conclusions}

Nanostructured $\mathrm{TiO}_{2} / \mathrm{h}-\mathrm{BN}$ composite coatings have been successfully prepared using a new developed suspension HVOF spray process. The study shows the feasibility of obtaining multi-scaled hierarchically nano-structured surfaces by introducing a liquid phase in the feedstock. h-BN disperses agglomerates in the nano-feedstock during deposition process and also inhibits the anatase-to-rutile transformation. The nano-feature of feedstock is thus well-preserved and the sintering of $\mathrm{TiO}_{2}$ is hindered with a decrease of rutile content from 70 to $61 \%$ when the h-BN addition changes from 0 to $15 \mathrm{wt} \%$. The addition of h-BN has a significant effect on the hydrophilic/ hydrophobic performance by changing the coating topography. The contact angles are $0^{\circ}$ and $11^{\circ}$ respectively for the coatings without and with $5 \mathrm{wt} \% \mathrm{~h}-\mathrm{BN}$ addition. With the increase of h-BN addition, the coatings show superhydrophobic with water contact angle nearly $170^{\circ}$ on $15 \mathrm{wt} \% \mathrm{~h}-\mathrm{BN}$ addition. The superhydrophobicity is maintained over time (13 months to date) and remains stable after exposure to visible light. The surface maintains superhydrophobicity after an adhesion tape test, which proves that the nanofeatures are fairly strong bond to the coatings. The surface remains to be hydrophobic even the coating surface experiences a serve damage (wear test) although the coating materials are intrinsically hydrophilic. All resultant coatings have high adhesion strengths with the substrate (45.551.7 MPa) which are comparable to conventional HVOF sprayed coating. This study therefore highlights a potential route for the industrial preparation of robust, water-repellent coatings. If manufacturing challenges, including reproducibility, can be overcome then potential uses for such durable superhydrophobic coatings include antifouling applications such as aeroplane wings, ship hulls, offshore wind turbine blades, or the above-deck structures on ice breaker vessels.

\section{Acknowledgements}

The authors are grateful to Prof. Phil Bartlett for the discussion on wetting. The work is supported by the China Scholarship Council (CSC), TWI Limited (Cambridge, UK), the Royal Society (IE111270) and the Royal Academy of Engineering (1314RECI080). The authors would also like to thank Mr Andrew K. Tabecki from the Surface Engineering section of TWI for his assistance with coating deposition and NEXUS group (Newcastle University, UK) for their assistance with XPS analysis.

\section{References}

1 B. N. Sahoo and B. Kandasubramanian, RSC Adv., 2014, 4, 22053-22093.

2 S. Pan, R. Guo and W. Xu, AIChE J., 2014, 60, 2752-2756.

3 S. Pan, A. K. Kota, J. M. Mabry and A. Tuteja, J. Am. Chem. Soc., 2013, 135, 578-581. 
4 S. Pan, R. Guo and W. Xu, Soft Matter, 2014, 10, 8800-8803. 5 Y. Lu, S. Sathasivam, J. Song, C. R. Crick, C. J. Carmalt and I. P. Parkin, Science, 2015, 347, 1132-1135.

6 S. Pan, R. Guo and W. Xu, Soft Matter, 2014, 10, 9187-9192.

7 J. Zhang, B. Li, L. Wu and A. Wang, Chem. Commun., 2013, 49, 11509-11511.

8 L. Xu, D. Zhu, X. Lu and Q. Lu, J. Mater. Chem. A, 2015, 3, 3801-3807.

9 W. Barthlott and C. Neinhuis, Planta, 1997, 202, 1-8.

10 T. Young, Philos. Trans. R. Soc. London, 1805, 95, 65-87.

11 R. N. Wenzel, Ind. Eng. Chem., 1936, 28, 988-994.

12 A. B. D. Cassie and S. Baxter, Trans. Faraday Soc., 1944, 40, 546.

13 R. Jia, Y. Bai and T. Li, Mater. Lett., 2005, 59, 4010-4012.

14 A. Pakdel, C. Zhi, Y. Bando, T. Nakayama and D. Golberg, ACS Nano, 2011, 5, 6507-6515.

15 G. Fan and F. Li, AIChE J., 2012, 58, 2639-2649.

16 G. Azimi, R. Dhiman, H.-M. Kwon, A. T. Paxson and K. K. Varanasi, Nat. Mater., 2013, 12, 315-320.

17 C. Lee, J. Drelich and Y. Yap, Langmuir, 2009, 25, 4853-4860. 18 L. H. Li and Y. Chen, Langmuir, 2010, 26, 5135-5140.

19 A. Pakdel, X. Wang, Y. Bando and D. Golberg, Acta Mater., 2013, 61, 1266-1273.

20 W. Tillmann, E. Vogli, I. Baumann, G. Matthaeus and T. Ostrowski, J. Therm. Spray Technol., 2008, 17, 924-932.

21 T. Varis, J. Knuuttila, E. Turunen, J. Leivo, J. Silvonen and M. Oksa, J. Therm. Spray Technol., 2007, 16, 524-532.

22 A. Killinger, R. Gadow, G. Mauer, A. Guignard, R. Vassen and D. Stover, J. Therm. Spray Technol., 2011, 20, 677-695.

23 E. Gozali, S. Kamnis and S. Gu, Surf. Coat. Technol., 2013, 228, 176-186.

24 M. Gardon and J. M. Guilemany, J. Therm. Spray Technol., 2014, 23, 577-595.

25 C. Deiana, E. Fois, S. Coluccia and G. Martra, J. Phys. Chem. $C$, 2010, 114, 21531-21538.

26 G. Darut, H. Ageorges, A. Denoirjean and P. Fauchais, Surf. Coat. Technol., 2013, 217, 172-180.

27 F. L. Toma, D. Sokolov, G. Bertrand, D. Klein, C. Coddet and C. Meunier, J. Therm. Spray Technol., 2006, 15, 576-581.

28 G. Bolelli, V. Cannillo, L. Lusvarghi and T. Manfredini, Wear, 2006, 261, 1298-1315.

29 C. K. Muoto, E. H. Jordan, M. Gell and M. Aindow, J. Therm. Spray Technol., 2012, 21, 1309-1321.

30 R. Jaworski, L. Pawlowski, F. Roudet, S. Kozerski and A. Le Maguer, J. Therm. Spray Technol., 2008, 17, 73-81.

31 K. VanEvery, M. J. M. Krane and R. W. Trice, Surf. Coat. Technol., 2012, 206, 2464-2473.
32 G. B. Filofteia-Laura Toma, D. Klein, C. Coddet and C. Meunier, J. Therm. Spray Technol., 2006, 15, 587-592.

33 H. Kassner, R. Siegert, D. Hathiramani, R. Vassen and D. Stoever, J. Therm. Spray Technol., 2008, 17, 115-123.

34 R. Jaworski, L. Pawlowski, F. Roudet, S. Kozerski and F. Petit, Surf. Coat. Technol., 2008, 202, 2644-2653.
35 P. Fauchais, G. Montavon, R. S. Lima and B. R. Marple, J. Phys. D: Appl. Phys., 2011, 44, 1-53.

36 F. L. Toma, G. Bertrand, D. Klein, C. Coddet and C. Meunier, J. Therm. Spray Technol., 2006, 15, 587-592.

37 G. Bolelli, J. Rauch, V. Cannillo, A. Killinger, L. Lusvarghi and R. Gadow, J. Therm. Spray Technol., 2009, 18, 35-49.

38 V. R. Srivatsan and A. Dolatabadi, J. Therm. Spray Technol., 2006, 15, 481-487.

39 R. Haubner, B. Lux, G. Petzow and R. Weissenbacher, High performance non-oxide ceramics II, Springer, 2011.

40 A. Davis, Y. H. Yeong, A. Steele, I. S. Bayer and E. Loth, ACS Appl. Mater. Interfaces, 2014, 6, 9272-9279.

41 E. Bannier, G. Darut, E. Sanchez, A. Denoirjean, M. C. Bordes, M. D. Salvador, E. Rayon and H. Ageorges, Surf. Coat. Technol., 2011, 206, 378-386.

42 M. S. P. Francisco and V. R. Mastelaro, Chem. Mater., 2002, 14, 2514-2518.

43 Boron Nitride, BN Ceramic Properties, http:/accuratus.com/ boron.html, (accessed 9th, December, 2014).

44 F. X. Ye, A. Ohmori, T. Tsumura, K. Nakata and C. J. Li, J. Therm. Spray Technol., 2007, 16, 776-782.

45 Y. Liu, J. Huang, S. Ding, Y. Liu, J. Yuan and H. Li, J. Therm. Spray Technol., 2013, 22, 1053-1062.

46 M. M. Ottakam Thotiyl, S. A. Freunberger, Z. Peng, Y. Chen, Z. Liu and P. G. Bruce, Nat. Mater., 2013, 12, 1050-1056.

47 Y. Zhu and C. Ding, J. Eur. Ceram. Soc., 2000, 20, 127-132.

48 A. Pakdel, Y. Bando and D. Golberg, ACS Nano, 2014, 8, 10631-10639.

49 T. Ltd, Superhydrophilic coating produced at TWI by suspension high velocity oxy-fuel spraying, http://www.twiglobal.com/superhydrophilic/, (accessed 19th, February, 2015).

50 T. Ltd, Superhydrophobic coating produced by suspension high velocity oxy-fuel spraying, http://www.twi-global.com/ superhydrophobic/, (accessed 19th, February, 2015).

51 S. X. Zhou, X. F. Ding and L. M. Wu, Prog. Org. Coat., 2013, 76, 563-570.

52 J. E. Samad and J. A. Nychka, Bioinspiration Biomimetics, 2011, 6, 016004.

53 D. M. Spori, T. Drobek, S. Zürcher and N. D. Spencer, Langmuir, 2010, 26, 9465-9473.

54 D. Quéré, Annu. Rev. Mater. Res., 2008, 38, 71-99.

55 N. Stevens, C. I. Priest, R. Sedev and J. Ralston, Langmuir, 2003, 19, 3272-3275.

56 O. M. Moon, B. C. Kang, S. B. Lee and J. H. Boo, Thin Solid Films, 2004, 464-465, 164-169.

57 E. Bittoun and A. Marmur, Langmuir, 2012, 28, 13933-13942.

58 B. Bhushan and M. Nosonovsky, The rose petal effect and the modes of superhydrophobicity, 2010.

59 F. Wang, F. C. Lv, Y. P. Liu, C. R. Li and Y. Z. Lv, J. Adhes. Sci. Technol., 2013, 27, 58-67.

60 A. Pakdel, Y. Bando and D. Golberg, Langmuir, 2013, 29, 7529-7533. 